\title{
Evidence and ethics in public health: the experience of SARS in Canada
}

\author{
Ross E.G. Upshur \\ Professor, Department of Family and Community Medicine, \\ Canada Research Chair in Primary Care Research, \\ University of Toronto \\ Email:ross.upshur@sunnybrook.ca
}

\begin{abstract}
Making decisions on the basis of evidence is a central tenet of all health-care disciplines, including public health. However, it is not entirely clear what it means to base decisions on evidence; debates on evidence-based approaches often lack a clear understanding of the nature of evidence and obscure the normative underpinnings of evidence. Public health decision making requires an acceptance of limitations such as the availability of funding for research to provide complete evidence for any given decision, the ethical constraints on the creation of certain types of evidence and the ongoing dilemma between the need to take action and the need to gather more information. Using the example of the SARS outbreak in Canada, the inter-relationships between evidence and ethics are explored. I outline a set of critical questions for the global public health community to discuss regarding the nature of the relationship between evidence-based public health practice and ethics.
\end{abstract}

It is not the fault of Hill or Doll or Hammond that they cannot produce evidence in which a thousand children of teen age have been laid under a ban that they shall never smoke, and a thousand more chosen at random from the same age group have been under compulsion to smoke at least thirty cigarettes a day. If that type of experiment could be done, there would be no difficulty. ${ }^{1}$ RA Fisher, 1958

We live in an era where all decisions must be evidence based. This is as much the case for public health as it is for clinical care. However, much depends on how evidence is defined and what counts as a legitimate claim to being evidential. Sorting these issues out is not a straight forward matter. In this paper, I raise some critical issues regarding the use of evidence in public health in the process of making choices and reaching conclusions, and the ethical constraints involved in this decision making. I use as an example the public health response to the SARS outbreak in Canada.

\section{Historical introduction}

Debates about evidence have existed in public health for a long time before the current era of evidence-based approaches to health services and care delivery. Indeed the quotation from Sir Ronald Fisher is directed against the early cohort studies by Bradford Hill and Doll in the 1950s showing an association between smoking and bronchogenic carcinoma in physicians. In his paper, Cigarettes, Cancer and Statistics, Fisher wrote:

Before one interferes with the peace of mind and habits of others, it seems to me that the scientific evidence - the exact weight of the evidence free from emotion - should be rather carefully examined. ${ }^{1}$

In Fisher's theory of knowledge, there are three necessary requirements to be met before any claim can be made that an observation is evidential:

1. There must be randomisation

2. There must be replication

3. There must be an appropriate control group.

The type of observational study Bradford Hill and Doll conducted failed one of the tests and therefore failed to meet Fisher's standard required of scientific evidence. Most public health practitioners are aware of Bradford Hill's response, which was distilled into a set of considerations required for drawing causal inferences. ${ }^{2}$ The issue remains unresolved, though few among us would take Fisher seriously and propose a randomised controlled trial of smoking in adolescents.

\section{Properties of evidence}

We may think that we have gotten past this impasse in the 21 st century. A quick review of the literature will persuade us that evidence-based approaches are ascendant and admit to no opposition. However, it is not entirely clear what it means to be evidence based, in a context where the key term, evidence, is seldom defined. I have argued elsewhere that evidence, in the form of published studies in the peer reviewed literature (or, by extension, a report from a public health organisation), has certain intrinsic properties, among them being its provisional and defeasible nature, 
meaning, that all evidence is capable of being overturned or modified in light of new findings. ${ }^{3}$ Thus evidence can be understood, particularly in public health decision making, from a more pragmatic perspective. Evidence is only one form of considered information that forms the knowledge base required for decision making. Indeed, evidence, as currently understood, does not exhaust the range of knowledge relevant to decision making. Given this definition of evidence, basing decisions on evidence is to rest such decisions on a shifting foundation. ${ }^{4}$

Computational constraints make it almost certain that we will more often than not be in possession of imperfect and limited evidence for any given decision. This means that a degree of uncertainty will pervade almost all decisions. As well, because of historical traditions, certain health disciplines have not been committed to the production of certain types of evidence. Funding priorities make some public health interventions less likely to have an accumulated body of evidence of a particular type (think here of restaurant inspection and randomised control trials). There are thus features of evidence that are seldom acknowledged or systematically addressed. Simply put, if evidence is to be available to inform decisions across the varied contexts of health care delivery, then efforts must be made to assure that research questions and research resources are devoted to them all. Finally, as the Fisher quotation illustrates, there are ethical constraints on the creation of certain types of evidence.

\section{Evidence and ethics}

In public health, there is an inherent tension between the credibility and security of evidence relative to any public health action or program that may be contemplated, and the need to take concerted action to promote health and prevent illness. Where large swathes of uncertainty exist, such uncertainty in a public health context cannot easily be resolved by soliciting preferences for care as is the case in clinical medicine. This difficulty is most starkly experienced in matters regarding health protection. An example is the severe acute respiratory syndrome (SARS) outbreak in $2003 .^{5}$

A newly discovered pathogen spread quickly around the world, playing particular havoc in the province of Ontario, Canada. We now know that SARS was caused by a coronavirus and that it exerted most of its effect on highly exposed patients in hospital settings. The community impact was modest. Yet in the early months of 2003, the exact nature of the virus was unknown. The possibility that the virus could spread in the community with potentially high morbidity and mortality was real and significant harm to the community could not be ruled out. Lacking any other form of effective intervention, public health authorities in Ontario imposed strict infection control measures including the use of quarantine for those potentially exposed to the virus. This decision was not based on anything resembling what counts for evidence in current evidence-based frameworks. The decision was a justifiable use of public health powers to contain the threat of a potentially serious epidemic. As subsequent analysis has shown, quarantine was indeed effective in helping to blunt the spread of the virus. ${ }^{6}$ Does this, though, establish an evidence base for quarantine?

The SARS experience exposed serious deficiencies in the capacity of modern health-care systems to respond to novel pathogens. In the aftermath of the SARS epidemic in Canada, several commissions of enquiry were held to learn lessons and propose reforms to the way in which public health is structured and funded in Canada. One of the most influential enquiries was chaired by Justice Archie Campbell and made a series of recommendations, including the following:

That the precautionary principle, which states that action to reduce risk need not await scientific certainty, be expressly adopted as a guiding principle throughout Ontario's health, public health and worker safety systems by way of policy statement, by explicit reference in all relevant operational standards and directions, and by way of inclusion, through preamble, statement of principle, or otherwise, in the Occupational Health and Safety Act, the Health Protection and Promotion Act, and all relevant health statutes and regulations.

That in any future infectious disease crisis, the precautionary principle guide the development, implementation and monitoring of procedures, guidelines, processes and systems for the early detection and treatment of possible cases. ${ }^{7}$

Justice Campbell considered that this was the most important message to be derived from the SARS epidemic in Canada. He noted that failure to heed this principle was at the core of a previous public health failing regarding the protection of the blood supply. Subsequently, the precautionary principle was introduced into the regulations of Ontario public health law.

Law and ethics are by no means one and the same thing and ethics do not reduce to the law. It is also the case that the precautionary principle admits to several, somewhat contrasting formulations. However, an important lesson was drawn by the Campbell Commission in the case of the Ontario SARS outbreak. Public health practitioners and agencies tasked with the mission of protecting and promoting health will always be mediating between the need to take action and the need to gather more information. Action which is evidence based, while desirable, may not be achievable in all circumstances. In such cases, having a clear normative mandate is required. Campbell recognised that this particular normative mandate is held only by public health in modern democracies. 
Several scholars articulating ethical frameworks for public health action have stressed the importance of having information on the effectiveness of the proposed intervention as a necessary condition before acting. ${ }^{8,9}$ Such a requirement may be overly constraining, particularly in cases of rapidly evolving threats to community health. Others have argued that when public health officials take action in a precautionary manner to secure public health goods that in some way curtails established civil liberties there is a reciprocal obligation on the part of the public health authorities to support those affected, and if necessary provide compensation. ${ }^{10}$ This condition of reciprocity recognises that there may be circumstances when public health authorities will act when such action was not required.

Several questions for sustained discussion in global public health emerge from the above experience. Is precaution appropriate to all public health interventions or only to communicable diseases outbreaks or disasters? The emerging patterns of obesity in the developed world prompt the question of whether some intervention based on precaution is required. Do thresholds for action based on evidence vary between communicable diseases, chronic diseases, health promotion and environmental health? How does a commitment to practising evidence-based public health align with calls for public health to address social justice and issues of health inequity? If, as some argue, the moral basis of public health is rooted in social justice, then it would follow that a very different vision of evidence would need to be articulated, one less focused on systematic reviews and randomised controlled trials. ${ }^{11}$ Michael Marmot has recently written on how standards of evidence may need to be redefined and expanded if action on the determinants of health is not to be plagued by inaction. ${ }^{12}$

Austin Bradford Hill acknowledged the moral epistemology of public health. In the concluding section of his famous paper on causation he noted the following:

On fair evidence we might take action on what appears to be an occupational hazard, e.g. we might change from a probably carcinogenic oil to a non-carcinogenic oil in a limited environment and without too much injustice if we are wrong. But we should need very strong evidence before we made people burn a fuel in their homes that they do not like or stop smoking the cigarettes and eating the fats and sugar that they do like. In asking for very strong evidence I would, however, repeat emphatically that this does not imply crossing every ' $t$ ', and swords with every critic, before we act. ${ }^{2}$

As we move forward to embrace more evidence-based approaches, we would be wise to have a sustained discussion on precisely what constitutes fair and strong evidence, and when claims to evidence are in alignment with or in opposition to the values and mission of public health. Such a discussion is likely a constitutive element of public health practice.

\section{Conclusion}

Evidence in health care is provisional and capable of being overturned, modified, refuted or superseded by better evidence. It is finite in its application and utility. There is a very important sense in which evidence exists to become obsolete. In some ways the vision, mission and values of public health, when clearly articulated, provide a sufficient guide to action, even in the absence of evidence. This simply means that both will be contested and the need for reasoned public discussion on the nature of both evidence and the goals and values of public health will not soon be discarded.

\section{References}

1. Fisher RA. Cigarettes, Cancer and Statistics. Cent Rev 1958; 2: 151-66. Available at: http://digital.library.adelaide.edu.au/coll/ special/fisher/274.pdf (Cited 17 October 2011).

2. Hill AB. The environment and disease: association or causation? Proc R Soc Med 1965; 58: 295-300.

3. Upshur REG. Seven characteristics of medical evidence. J Eval Clin Pract 2000; 6: 93-7. doi:10.1046/j.13652753.2000.00244.x

4. Upshur REG. If not evidence, then what? Or does medicine really need a base? J Eval Clin Pract 2002; 8: 113-9. doi:10.1046/j.1365-2753.2002.00356.x

5. Naylor $\mathrm{CD}$, Chantler $\mathrm{C}$, Griffiths $\mathrm{S}$. Learning from SARS in Hong Kong and Toronto. JAMA 2004; 291: 2483-7. doi:10.1001/jama.291.20.2483

6. Bondy SJ, Russell ML, Laflèche JM, Rea E. Quantifying the impact of community quarantine on SARS transmission in Ontario: estimation of secondary case count difference and number needed to quarantine. BMC Public Health 2009; 9: 488. Available at: http://www.biomedcentral.com/1471-2458/9/488 (Cited 17 October 2011).

7. Campbell A. SARS Commission, Executive Summary. Spring of Fear. Volume 1 December 2006. Available at: http:// www.health.gov.on.ca/english/public/pub/ministry_reports/ campbel106/online_rep/V1C3.html (Cited 17 October 2011).

8. Childress JF, Faden RR, Gaare RD, Gostin LO, Kahn J, Bonnie RJ et al. Public health ethics: mapping the terrain. J Law Med Ethics 2002; 30: 170-8. doi:10.1111/j.1748-720X.2002. tb00384.x

9. Kass NE. An ethics framework for public health. Am J Public Health 2001; 91: 1776-82. doi:10.2105/AJPH.91.11.1776

10. Upshur RE. Principles for the justification of public health intervention. Can J Public Health 2002; 93: 101-3.

11. Powers M, Faden R. Social justice: the moral foundations of public health and health policy. Oxford: Oxford University Press, 2006.

12. Marmot M, Friel S. Global health equity: evidence for action on the social determinants of health. J Epidemiol Community Health 2008; 62: 1095-7. doi:10.1136/jech.2008.081695 